\title{
DIPLOMASI BUDAYA PEMERINTAH PROVINSI KALIMANTAN SELATAN DALAM FESTIVAL BANJAR 2018-2019
}

\author{
Salsabila Andi Akil ${ }^{1 *}$, Indra Kusumawardhana ${ }^{2}$ \\ Institut Komunikasi dan Bisnis LSPR, Jakarta, Indonesia \\ *salsabilaakil@yahoo.co.id
}

\begin{abstract}
Indonesia conduct cultural diplomacy activities not only by central government but also regional government, including Provincial Government of South Kalimantan. The purpose of this research is to understand how Provincial Government of South Kalimantan conducted cultural diplomacy in Festival Banjar 2018-2019. The concepts used in this research are Cultural Diplomacy by Gienow-Hecht and Donfried and Paradiplomacy by Duchacek. This research uses qualitative research method and constructivist paradigm. The results of this research reveal that Festival Banjar 2018-2019 is a form of cultural diplomacy carried out by sub-national actor, in this case Provincial Government of South Kalimantan. Festival Banjar 2018-2019 is a cultural diplomacy agent practice belongs to mixed model; agenda to promote South Kalimantan culture and tourism; vehicle through South Kalimantan art and floating market simulation; target audience are the diplomatic corps and foreign societies. Provincial Government of South Kalimantan as a sub-national actor also related to paradiplomacy where the implementation involves two main types of paradiplomatic activities, such as lobbying through interactive talk shows with the target audiences; and media exposure during the event.
\end{abstract}

Keywords: cultural diplomacy, paradiplomacy, provincial government of south kalimantan, festival banjar 2018-2019

\begin{abstract}
Abstrak
Indonesia sebagai negara dengan beragam kebudayaan dimanfaatkan oleh pemerintahnya untuk melakukan aktivitas diplomasi budaya, tidak hanya pemerintah pusat namun juga pemerintah daerah, khusunya Pemerintah Provinsi Kalimantan Selatan karena kurangnya awareness dari masyarakat asing mengenai budaya dan pariwisata Kalimantan Selatan. Tujuan penelitian ini yaitu memahami diplomasi budaya yang dilakukan Pemerintah Provinsi Kalimantan Selatan dalam Festival Banjar 2018-2019. Konsep yang digunakan dalam penelitian ini yaitu Diplomasi Budaya menurut Gienow-Hecht dan Donfried dan Paradiplomasi oleh Duchacek. Penelitian ini menggunakan metode penelitian kualitatif dan paradigma konstruktivis. Hasil penelitian ini mengungkapkan bahwa Festival Banjar 2018-2019 merupakan wujud diplomasi budaya yang dilakukan aktor sub-nasional dalam hal ini Pemerintah Provinsi Kalimantan Selatan. Festival Banjar merupakan praktik agent diplomasi budaya yang menggunakan mixed model; agenda untuk mempromosikan budaya dan pariwisata Kalimantan Selatan; vehicle melalui kesenian Kalimantan Selatan dan simulasi pasar terapung; target audience yaitu korps diplomatik dan masyarakat asing. Pemerintah Provinsi Kalimantan Selatan sebagai aktor sub-nasional yang melakukan aktivitas diplomasi budaya terkait dengan konsep paradiplomasi dimana pelaksanaannya melibatkan dua pola pendukung, yaitu lobi yang dilakukan oleh aktor sub-nasional melalui talk show interaktif; dan media yang terlibat dalam peliputan kegiatan Festival Banjar 20182019.
\end{abstract}

Kata Kunci: diplomasi budaya, paradiplomasi, pemerintah provinsi kalimantan selatan, festival banjar 2018-2019 


\section{PENDAHULUAN}

Keberagaman budaya Indonesia menjadi modal dalam melakukan diplomasi budaya. Bahkan sejak zaman Presiden Soekarno hal ini sering dilakukan ketika melaukan hubungan diplomatik. Seiring dengan terjadinya perubahan zaman maka terjadi perubahan pula dalam tatanan politik internasional. Banyak negara saat ini menggunakan budaya dan kebiasaan yang berlaku pada negaranya sehingga dapat diterima pihak manapun. Dahulu suatu negara hanya bergantung pada kekuatan militernya dalam memenuhi kepentingan negaranya, maka saat ini negara-negara berlomba untuk memenuhi kepentingannya melalui kekuatan lain seperti budaya dan kebiasaan.

Budaya merupakan kegiatan yang mampu diterima oleh siapapun. Sebab kegiatan-kegiatan kebudayaan dilakukan dengan cara yang asik dan menarik sehingga audience tidak sadar bahwa dirinya telah terpersuasi menjadi penikmat suatu budaya tertentu. Sama halnya dengan Indonesia, data dari Kementerian Pariwisata Republik Indonesia menunjukkan bahwa budaya merupakan faktor terbesar yang menarik minat wisatawan untuk berkunjung ke Indonesia. Faktor yang mempengaruhi kedatangan wisatawan mancanegara ke Indonesia yaitu 60 persen karena budaya, 35 persen karena alam, dan 5 persen karena faktor buatan seperti meeting, incentive, conference, dan exhibition (MICE), wisata olahraga, dan hiburan (Rostanti, 2017).

Hal tersebut tentunya merupakan kekuatan dan keutungan yang dimiliki Indonesia sebagai negara kepulauan sehingga banyak kebudayaan yang dapat dilihat dan menarik bagi wisatawan asing. Suatu negara dalam memperkenalkan budayanya kepada negara lain salah satunya dilakukan melalui aktivitas diplomasi budaya. Diplomasi budaya adalah salah satu bentuk diplomasi yang mana pelaksanaannya melibatkan lembaga, organisasi, kelompok, maupun agen kebudayaan yang bertujuan untuk menarik dukungan publik atas kebijakan luar negeri suatu negara (Emilia, 2013). Dengan melakukan aktivitasnya secara menarik melalui kegiatan kebudayaan dalam jalur diplomasi budaya, maka tentunya akan lebih mudah bagi suatu negara untuk mempersuasi negara lain dalam mencapai tujuan politiknya. Salah satu negara yang melakukan aktivitas diplomasi budaya dalam memperkenalkan negaranya ialah Indonesia.

Jika dahulu aktivitas diplomasi budaya identik dengan aktivitas yang dilakukan pemerintah nasional suatu negara, namun saat ini hal tersebut telah mengalami perkembangan dalam pelaksanaannya. Aktor baru yang muncul dalam pelaksanaan diplomasi budaya ialah aktor sub-nasional dan supranasional (Zamorano, 2016). Dalam kerangka diplomasi, Mantan Presiden Republik Indonesia Indonesia Susilo Bambang Yudhyono dalam sambutannya didepan para pengusaha Australia di Canberra pada 11 Maret 2010 mempersilahkan pengusaha-pengusaha untuk melakukan kerjasama dengan pemerintah daerah di Indonesia. Karena tanpa adanya kerjasama antara pemerintah daerah dan pihak asing pertumbuhan ekonomi daerah dinilai akan sulit didorong untuk berkembang lebih cepat (Mukti, 2013).

Banyaknya kebijakan-kebijakan dan peristiwa yang terjadi secara global ternyata tidak hanya memberikan pengaruh kepada negara secara keseluruhan melainkan juga unit yang lebih kecil, yaitu daerah-daerah. Pemerintah pusat pun mendukung aktivitas pemerintah daerah untuk melebarkan sayapnya bekerja sama dengan pihak-pihak asing yang dapat memajukan daerahnya. Menunjukkan bahwasanya saat ini diplomasi budaya tidak hanya dilakukan oleh aktor negara namun juga aktor nonnegara.

Salah satu daerah di Indonesia yang mempraktikkan aktivitas diplomasi budaya ialah Kalimantan Selatan. Kurangnya 
awareness dari masyarakat asing mengenai budaya dan pariwisata Kalimantan Selatan terlihat dari sektor pariwisata Kalimantan Selatan yang belum mengalami pertumbuhan yang signifikan. Dilihat dari data Badan Pusat Statistik (2018) bahwa jumlah tamu asing yang berkunjung ke Kalimantan Selatan belum terbilang besar. Kalimantan Selatan menempati urutan ke-21 pada tahun 2017 dengan jumlah tamu asing sebesar 13 ribu orang dan urutan ke-20 pada tahun 2018 dengan jumlah tamu asing sebesar 12 ribu orang. Angka tersebut menunjukkan bahwa masih banyak wisatawan asing yang belum tertarik untuk berkunjung ke Kalimantan Selatan.

Menurut mantan diplomat Indonesia, Kartini Sabekti (2003) diplomasi budaya merupakan kegiatan yang rajin dilakukan oleh pemerintah Indonesia. Diplomasi budaya yang dilakukan bertujuan untuk mencerminkan citra positif Indonesia di dunia internasional serta menarik wisatawan asing untuk berkunjung dan berinvestasi di Indonesia. Diplomasi budaya biasanya dilakukan melalui berbagai festival, baik yang diselenggarakan di luar negeri maupun di Indonesia. Festival dianggap dapat menarik minat besar dari khalayak ramai, sehingga terjadilah hubungan interaksi yang aktif antarbangsa dan juga antarmanusianya.

Aktor sub-nasional yang dimaksud dalam penelitian ini ialah Pemerintah Provinsi Kalimantan Selatan. Pemerintah Provinsi Kalimantan Selatan bersama Kerukunan Bubuhan Banjar Jabodetabek yang didukung oleh Kementerian Luar Negeri Republik Indonesia melakukan kegiatan Festival Banjar yang telah diadakan selama dua tahun yaitu pada 2018 dan 2019 dengan tujuan memberi kesempatan bagi publik dalam negeri dan luar negeri untuk dapat mengenal potensi Kalimantan Selatan secara lebih mendalam di bidang budaya, ekonomi, dan pariwisata.

Festival Banjar pertama kali dilaksanakan pada tahun 2018. Festival ini awalnya terbentuk dari kegiatan rutin silaturahmi tahunan masyarakat Banjar di Jabodetabek yang kemudian dikembangkan menjadi sebuah festival budaya dengan tujuan mempromosikan budaya dan pariwisata Kalimantan Selatan. Beberapa kegiatan yang ditampilkan dalam Festival Banjar 2018, yaitu pameran potensi Kalimantan Selatan, parade budaya Banjar, prosesi adat, dan bazaar kuliner khas Kalimantan Selatan. Pada tahun 2019 Festival Banjar kembali digelar dengan agenda kegiatan atraksi simulasi pasar terapung, replika Aruh Adat Dayak dengan judul 'Doa Bagi Bumi', silaturahmi keluarga Banjar sedunia, bazaar kuliner Banjar, serta pentas seni dan karnaval budaya Banjar dan Dayak Meratus. Fokus kegiatan Festival Banjar 2018 dan Festival Banjar 2019 terletak pada simulasi pasar terapung yang merupakan destinasi wisata unggulan Kalimantan Selatan.

Sumiyati dan Murdiyanto (2018) mengatakan bahwa pameran merupakan salah satu elemen penting dalam sebuah aktivitas untuk mempromosikan budaya dan pariwisata daerah, sebab pameran dapat memberikan gambaran ataupun informasi yang jelas mengenai objek pariwisata, kebudayaan, hingga kuliner khas daerah. Hal tersebut berguna dalam membangun proses komunikasi antara pemerintah dan target audience yang bertujuan untuk mencapai tujuan dari aktivitas yang dilakukan.

Menurut Direktorat Warisan dan Diplomasi Budaya Direktorat Jenderal Kebudayaan Kementerian Pendidikan dan Kebudayaan dalam buku Pedoman Diplomasi Budaya (2018) tujuan diadakannya diplomasi budaya, diantaranya meningkatkan citra dan apresiasi terhadap Indonesia di forum internasional, meningkatkan pengaruh budaya Indonesia di tingkat internasional, dan meningkatkan pemahaman, kerja sama, dan hubungan baik dengan negara lain di bidang kebudayaan. Pemerintah Provinsi Kalimantan Selatan dalam Festival Banjar 2018-2019 ingin menunjukkan kesan yang baik kepada 
masyarakat internasional mengenai Kalimantan Selatan sebagai bagian dari Indonesia melalui beragam kebudayaan yang ditampilkan dan lobi yang dilakukan kepada target audiens. Hal ini berperan dalam mencapai kepentingan nasional Indonesia sebagai negara yang memiliki citra baik, sehingga diharapkan dapat meningkatkan pengaruh dan juga kerja sama antara Indonesia dengan negara lain, khususnya dalam bidang kebudayaan.

Berdasarkan latar belakang di atas maka dilakukan penelitian lebih lanjut mengenai diplomasi budaya Pemerintah Provinsi Kalimantan Selatan dalam Festival Banjar 2018-2019. Mengingat bahwa saat ini aktor sub-nasional juga memiliki peran dalam melakukan diplomasi budaya. Penelitian ini menggunakan konsep diplomasi budaya menurut Gienow-Hecht dan Donfried (dalam Carbone, 2017) dengan empat elemen yang terdapat di dalamnya yaitu agent, agenda, vehicle, dan target audience, serta didukung oleh konsep paradiplomasi menurut Duchacek (1990).

Menurut Appel, Irony, Schmerz, dan Ziv (2008) diplomasi budaya ditandai dengan interaksi antar manusia yang memiliki kebudayaan berbeda melalui instrumen-instrumen yang berhubungan dengan kebudayaan, seperti kesenian secara umum, adat istiadat, tradisi dan kebiasaan, perilaku masyarakat, sejarah, musik, cerita rakyat, sikap, dan hubungan masyarakatnya.

Diplomasi budaya juga dapat didefinisikan sebagai upaya aktor untuk mengelola lingkungan internasional dengan membuat sumber daya budayanya dikenal di luar negeri dan/atau memfasilitasi transmisi budaya di luar negeri. Diplomasi budaya secara historis berarti kebijakan suatu negara untuk memfasilitasi ekspor budayanya (Cull, 2009).

Menurut Riordan (2005), saat ini aktor negara telah kehilangan monopolinya dalam melakukan hubungan internasional sebab munculnya aktor-aktor baru, salah satunya ialah aktor sub-nasional.
Dalam melakukan aktivitas diplomasi budaya, aktor non-negara penting untuk menciptakan lingkungan komunikasi yang terbuka dan transparan, seperti melibatkan target audience dalam kegiatan yang dilakukan (Jiang, 2015).

Gienow-Hecht dan Donfried (dalam Carbone, 2017) menyebutkan bahwa terdapat empat komponen utama dari diplomasi budaya yang digunakan untuk menganalisis semua fenomena yang berkaitan dengan hubungan internasional dan diplomasi budaya, yaitu: 1) agent; 2) agenda; 3) vehicle; dan 4) target audience.

Selain konsep diplomasi budaya, penelitian ini juga menggunakan paradiplomasi sebagai konsep pendukung. Paradiplomasi umumnya disebut dalam literatur akademik sebagai keterlibatan unit konstituen (wilayah) suatu negara dalam urusan internasional. Pemerintah daerah bekerja aktif dalam urusan internasional, seperti membuka misi perdagangan dan kebudayaan di luar negeri, menandatangani perjanjian dengan akor negara dan aktor non-negara lain, dan berpartisipasi dalam jaringan internasional mengenai kerja sama regional (Kuznetsov, 2015).

Terdapat empat pola yang mendukung aktivitas aktor sub-nasional dalam lingkup internasional. Pertama, yaitu tindakan lobi yang dilakukan oleh aktor subnasional sehingga menarik perhatian dan reaksi aktor ekstra-nasional. Kedua, yaitu aktor sub-nasional yang berpotensi menjadi target campur tangan atau suap dari pihak asing. Ketiga, yaitu pendanaan dari perusahaan transnasional yang ditujukan demi kepentingan mereka. Keempat, yaitu media asing dan domestik yang meliput tindakan aktor sub-nasional ke arena internasional

Namun dari empat pola tersebut hanya ada dua pola yang akan dibahas, yaitu tindakan lobi yang dilakukan oleh aktor subnasional sehingga menarik perhatian dan reaksi aktor ekstra-nasional, dan media asing dan domestik yang meliput tindakan aktor 
sub-nasional ke arena internasional, karena dua pola tersebut yang relevan dengan penelitian ini.

Penelitian sebelumnya dilakukan oleh Lestariningsih (2016) yang membahas mengenai Wonderful Indonesia Festival 2015 di Thailand sebagai diplomasi budaya Indonesia yang bertujuan untuk meningkatkan citra Indonesia dimata masyarakat dunia, khususnya Thailand. Wonderful Indonesia Festival 2015 di Thailand mengangkat tema The Amazing Borobodur. Penelitian ini menggunakan 7 dari 13 elemen kebudayaan John Lenczowski, yaitu exhibition, promotion of ideas, broadcasting, gifts, listening and according respect, religious diplomacy, dan art. Perbedaan antara penelitian yang dilakukan saat ini dengan penelitian sebelumnya, yaitu terletak pada elemen diplomasi budaya yang digunakan dalam menganalisis penelitian. Penelitian sebelumnya menggunakan tujuh elemen kebudayaan dari John Lenczowski, sedangkan penelitian saat ini menggunakan elemen diplomasi budaya dari GienowHecht dan Donfried. Wonderful Indonesia Festival 2015 bertujuan untuk mempromosikan budaya Indonesia secara keseluruhan di Thailand, sedangkan Festival Banjar 2018-2019 bertujuan untuk mempromosikan budaya Kalimantan Selatan kepada korps diplomatik dan masyarakat asing. Adapun dalam konteks paradiplomasi, penelitian sebelumnya yang dijadikan acuan dalam penelitian ini dilakukan oleh Suharyadi (2016) yang membahas mengenai paradiplomasi yang dilakukan oleh Pemerintah Kota Bandung dalam mempromosikan konsep Bandung sebagai Smart City melalui Asia Africa Smart City Summit (AASCS). Penelitian ini menggunakan empat pola yang mendukung aktivitas aktor sub-nasional dalam lingkup internasional. Perbedaan antara penelitian yang dilakukan saat ini dengan penelitian sebelumnya, yaitu penelitian sebelumnya membahas paradiplomasi yang dilakukan melalui kegiatan konverensi untuk mempromosikan konsep Bandung sebagai smart city, sedangkan pada penelitian saat ini membahas paradiplomasi yang dilakukan melalui kegiatan festival untuk mempromosikan budaya dan pariwisata Kalimantan Selatan.

Tujuan Penelitian ini yaitu untuk memahami diplomasi budaya Pemerintah Provinsi Kalimantan Selatan dalam Festival Banjar 2018-2019 melalui empat elemen diplomasi budaya menurut Gienow-Hecht dan Donfried (dalam Carbone, 2017), yaitu agent, agenda, vehicle, dan target audience, serta didukung oleh konsep paradiplomasi menurut Duchacek (1990).

\section{METODOLOGI}

Penelitian ini memfokuskan pada Diplomasi Budaya Pemerintah Provinsi Kalimantan Selatan dalam Festival Banjar 2018-2019. Teknik penelitian yang digunakan yaitu metode kualitatif. Penelitian kualitatif ialah penelitian yang lebih mengandalkan prinsip-prinsip interpretatif atau kritis dari ilmu sosial. Penelitian yang dibahas biasanya berupa makna dari sebuah kasus ataupun makna budaya. Penekanan yang dilakukan dalam penelitian kualitatif yaitu melakukan pemeriksaan terperinci terhadap kasus-kasus spesifik yang muncul dalam kehidupan sosial (Neuman, 2014). Lalu untuk mendapatkan hasil yang sesuai maka penelitian ini menggunakan paradigma konstruktivis.

Teknik pengumpulan data melalui data primer dan data sekunder. Data primer dikumpulkan peneliti melalui wawancara dengan pihak-pihak yang memahami mengenai Festival Banjar 2018-2019 dan Diplomasi Budaya yang menjadi fokus penelitian ini. Kelima informan yang dimaksud, yaitu Dina Dahliana dan Denny P. Sinaga dari Pemerintah Provinsi Kalimantan Selatan, M. Husni Thambrin dari Kerukunan Bubuhan Banjar 
Jabodetabek, serta Tia Sundari Waryono dan Azis Nurwahyudi dari Kementerian Luar Negeri Republik Indonesia. Data sekunder berupa dokumen-dokumen didapatkan peneliti melalui media online (berita online dan website lembaga negara) dan studi kepustakaan (buku dan penelitian sebelumnya).

\section{HASIL DAN PEMBAHASAN}

\section{Diplomasi Budaya Festival Banjar 2018- 2019}

Diplomasi budaya menurut Nye (dalam Carbone, 2017) merupakan upaya yang dilakukan oleh aktor-aktor yang terlibat untuk mempersuasi publik di negara lain melalui budaya, nilai, dan ide negara tersebut daripada melalui jalur militer

Seperti yang diungkapkan oleh Tia Sundari Waryono bahwa diplomasi budaya memiliki tujuan untuk meningkatkan citra suatu negara di hadapan publik asing maupun publik dalam negeri dengan menggunakan budaya sebagai tools dalam mencapai tujuan diplomasinya tersebut.

Pernyataan di atas sejalan dengan gagasan Raymond William yang dikutip dalam Ang, Isar, dan Mar (2015) yang menyatakan bahwa diplomasi budaya digunakan sebagai alat untuk mempromosikan identitas suatu bangsa atau yang ia sebut sebagai cultural policy of display.

Berdasarkan hal tersebut Indonesia sebagai negara yang memiliki keragaman budaya dimanfaatkan oleh pemerintahnya untuk melakukan kegiatan diplomasi budaya yang berbentuk festival. Festival Banjar 2018-2019 menyasar korps diplomatik dan masyarakat asing dengan tujuan mempromosikan budaya dan pariwisata Kalimantan Selatan agar dapat dikenal oleh publik yang luas.

\section{Pemerintah Provinsi Kalimantan Selatan Sebagai Agent dalam Festival Banjar 2018-2019}

Agent dalam diplomasi budaya adalah pihak-pihak yang terlibat dalam pelaksanaan kegiatan diplomasi budaya. Pelaksana tersebut tidak hanya dimaksudkan kepada aktor negara (state actor) tetapi juga aktor non-negara (non-state actor) (Carbone, 2017, p. 66).

Dina Dahliana selaku pihak dari Pemerintah Provinsi Kalimantan Selatan mengungkapkan bahwa Pemerintah Provinsi Kalimantan Selatan memiliki peran untuk memfasilitasi ide-ide dari Kerukunan Bubuhan Banjar Jabodetabek. Bagian utama yang bertugas dalam pelaksanaan Festival Banjar ialah Dinas Pariwisata yang bertugas sebagai pelaksana kegiatan.

M. Husni Thambrin dari Kerukunan Bubuhan Banjar Jabodetabek juga menambahkan bahwa Kerukunan Bubuhan Banjar Jabodetabek berperan sebagai insiator sekaligus pelaksana kegiatan Festival Banjar 2018-2019. Sebagai pelaku kebudayaan, Kerukunan Bubuhan Banjar Jabodetabek ingin memberikan dukungan terhadap perkembangan dan kegiatan kebudayaan daerah Kalimantan Selatan melalui Festival Banjar.

Dikarenakan banyaknya korps diplomatik yang hadir sebagai undangan maka Kementerian Luar Negeri Republik Indonesia juga berperan dalam mendukung dan memberi arahan terkait protokol hubungan luar negeri yang ada dalam kegiatan Festival Banjar 2018-2019. Hal diungkapkan oleh Tia Sundari Waryono selaku pihak dari Kementerian Luar Negeri Republik Indonesia.

Pemerintah Provinsi Kalimantan Selatan dalam Festival Banjar 2018-2019 memfasilitasi inisiasi yang dibentuk oleh Kerukunan Bubuhan Banjar Jabodetabek selaku perwakilan masyarakat Kalimantan Selatan dan pelaku kebudayaan yang ada di Jabodetabek. Sebagai pelaku kebudayaan yang terus berinteraksi dengan kebudayaan Kalimantan Selatan, Kerukunan Bubuhan Banjar Jabodetabek tentu mengetahui budaya apa yang menarik untuk 
diperlihatkan kepada target audience yang baru ingin mengenal ataupun yang gemar menikmati kebudayaan Kalimantan Selatan. Selain itu Pemerintah Provinsi Kalimantan Selatan juga melakukan koordinasi dengan Kementerian Luar Negeri Republik Indonesia sebagai lembaga negara yang membidangi urusan luar negeri untuk memberikan arahan terkait aktivitas diplomasi budaya yang ada dalam kegiatan ini.

Menurut Ada (2017), praktik diplomasi budaya memiliki tiga model utama, yaitu: 1) direct government supervision; 2) non-governmental agency; dan 3) mixed model (p. 52).

Model pertama, direct government supervision dicontohkan dengan French Institute yang aktif mempromosikan budaya dan bahasa Prancis di luar negeri merupakan lembaga yang secara langsung terkait dengan Kementerian Luar Negeri Perancis (Ada, 2017, p. 52).

Model kedua, non-governmental agency dicontohkan dengan British Council dan Japanese Foundation. British Council merupakan organisasi yang didirikan melalui Piagam Kerajaan Inggris yang didanai oleh Kementerian Luar Negeri Inggris, namun tidak terkait langsung oleh lembaga pemerintah tersebut (Ada, 2017, p. 52).

Model ketiga, yaitu mixed model dicontohkan dengan Goethe Institute dimana prinsip-prinsip diplomasi budayanya ditentukan oleh Kementerian Luar Negeri Jerman, namun dananya berasal dari Goethe Institute sendiri. Selain itu, mixed model juga mencakup pelaksanaan diplomasi budaya yang dilakukan oleh bentuk agent baru dalam diplomasi budaya, yaitu organisasi supranasional (EUNIC) dan aktor sub-nasional (Provinsi Quebec, Kanada) (Ada, 2017, p. 53).

Penelitian ini terkait dengan mixed model karena Festival Banjar 2018-2019 dilihat sebagai aktivitas diplomasi budaya yang dilakukan oleh aktor sub-nasional yaitu
Pemerintah Provinsi Kalimantan Selatan. Hal tersebut juga sesuai dengan konsep diplomasi budaya menurut Riordan (2005) bahwa saat ini negara telah kehilangan monopolinya dalam aktivitas diplomasi budaya yang diakibatkan oleh munculnya aktor-aktor baru seperti aktor sub-nasional. Hal tersebut dilihat sebagai akibat dari semakin banyaknya isu-isu dalam hubungan internasional yang memiliki keterkaitan langsung dengan isu-isu yang ada di daerah.

Dalam penelitian ini agent difokuskan pada Pemerintah Provinsi Kalimantan Selatan yaitu aktor sub-nasional yang tergolong ke dalam aktor non-negara. Pemerintah Provinsi Kalimantan Selatan sebagai aktor sub-nasional yang melakukan aktivitas diplomasi budaya terkait dengan konsep paradiplomasi yang ada dijelaskan pada sub-bagian berikutnya.

\section{Promosi Budaya dan Pariwisata Kalimantan Selatan Sebagai Agenda Festival Banjar 2018-2019}

Agenda berarti tujuan yang ingin dicapai oleh aktor dalam melakukan kegiatan diplomasi budayanya. Tujuan yang ingin dicapai dapat berbeda-beda tergantung dengan kegiatan yang dilakukan dan apa yang ingin disasar (Carbone, 2017, p. 66).

Tujuan diadakannya Festival Banjar 2018-2019 menurut Dina Dahliana ialah untuk mempromosikan budaya dan pariwisata Kalimantan Selatan kepada wisatawan nusantara dan mancanegara serta meningkatkan ekonomi masyarakat Kalimantan Selatan.

Hal serupa juga diungkapkan oleh M. Husni Thambrin bahwa Festival Banjar 2018-2019 bertujuan untuk memelihara kebudayaan Banjar sekaligus mempromosikannya kepada masyarakat yang lebih luas, dalam hal ini yaitu masyarakat dunia.

Tia Sundari Waryono mengatakan bahwa selama ini masyarakat luar negeri mengenal Indonesia hanya berdasarkan budaya populer, dengan adanya kegiatan 
Festival Banjar 2018-2019 diharapkan budaya-budaya lain juga ikut tersentuh. Selain itu tujuannya ialah untuk menjaga perdamaian, terutama dengan negara-negara tetangga dengan mendundang mereka sebagai tamu negara.

Berdasarkan penjelasan para informan di atas, maka diketahui bahwa tujuan Festival Banjar 2018-2019 yaitu untuk mempromosikan budaya dan pariwisata Kalimantan Selatan. Dalam kerangka nasional, diadakannya Festival Banjar 2018-2019 bertujuan untuk menampilkan Indonesia sebagai negara yang multi culture dan diharapkan dapat menjadi ide bagi budaya lainnya untuk ikut melakukan upaya promosi.

Pemerintah Provinsi Kalimantan Selatan memperkenalkan kebudayaan Kalimantan Selatan melalui ajang pameran dan simulasi budaya sehingga dapat lebih mudah dimengerti dan dikenali oleh target audience sebab dapat dilihat ciri-ciri dan kekhasannya secara langsung. Kegiatan Festival Banjar 2018-2019 yang dilakukan oleh Pemerintah Provinsi Kalimantan Selatan dapat menjadi ide bagi pemerintah daerah maupun aktor-aktor kebudayaan lainnya untuk ikut melakukan upaya promosi terutama bagi budaya yang belum terlalu dikenali oleh masyarakat lokal maupun internasional.

Hal tersebut sesuai dengan konsep diplomasi budaya menurut Cull (2009) yang mengungkapkan bahwa tujuan diplomasi budaya yang dilakukan oleh aktor yang terlibat ialah tidak lain untuk membuat sumber budayanya dikenal di negara lain. Festival Banjar 2018-2019 memiliki tujuan untuk mempromosikan budaya dan pariwisata Kalimantan Selatan. Hal ini didasari oleh kesan yang ditampilkan Indonesia sebagai negara dengan keragaman budaya, namun pada kenyataannya budaya Indonesia yang dikenal oleh masyarakat asing hanya budaya populer. Kurangnya awareness masyarakat asing terhadap budaya lain di Indonesia, khususnya
Kalimantan Selatan menjadi kesempatan bagi Pemerintah Provinsi Kalimantan Selatan dalam Festival Banjar 2018-2019 untuk dapat memperlihatkan bukti nyata bahwa keragaman budaya yang dimiliki oleh Indonesia benar adanya dan sama menariknya untuk dinikmati.

\section{Kesenian Kalimantan Selatan dan Simulasi Pasar Terapung sebagai Vehicle Festival Banjar 2018-2019}

Vehicle ialah cara yang ditempuh oleh para aktor-aktor diplomasi budaya untuk mencapai tujuan yang diharapkannya (Carbone, 2017, p. 67).

Menurut Dina Dahliana, dalam kerangka promosi pariwisata Kalimantan Selatan, Festival Banjar 2018-2019 mengangkat simulasi pasar terapung sebagai highlight kegiatan karena merupakan ikon dari Kalimantan Selatan. Semua tema kegiatan Festival Banjar mengambil tema wisata dan kebudayaan sebab wisata dan budaya Kalimantan Selatan yang memungkinkan untuk dijual ke luar daerah.

Sedangkan dalam kerangka promosi budaya Kalimantan Selatan, Festival Banjar 2018-2019 menampilkan kesenian khas Kalimantan Selatan berupa tarian, musik daerah, produk kerajinan seperti baju sasirangan, dan pertunjukan teater tradisional. Sebagaimana yang diungkapkan oleh M. Husni Thambrin.

Pasar terapung merupakan ciri khas yang membedakan Kalimantan Selatan dengan daerah lain yang ada di Indonesia. Tia Sundari Waryono setuju bahwa dalam mempromosikan pariwisata, simulasi pasar terapung yang dijadikan sebagai highlight kegiatan Festival Banjar 2018-2019 merupakan ciri khas yang memang harus selalu ditampilkan dalam setiap kegiatan promosi budaya dan pariwisata karena pasar terapung merupakan suatu hal yang berbeda sehingga mengingatkan masyarakat asing kepada Indonesia.

Sedangkan menurut Denny P. Sinaga, dalam mempromosikan 
kebudayaan, salah satu hal yang harus dilakukan adalah inovasi agar masyarakat yang menyaksikannya tidak jenuh. Sebab menurutnya, sifat budaya bukan statis melainkan dinamis yang mana dapat berubah ataupun dikembangkan seiring waktu.

Festival Banjar 2018-2019 memfokuskan kegiatannya pada kesenian Kalimantan Selatan berupa tarian, musik daerah, produk kerajinan seperti baju sasirangan, dan pertunjukan teater tradisional, serta simulasi pasar terapung. Simulasi pasar terapung tidak hanya menunjukkan kebiasaan masyarakat Kalimantan Selatan, namun didalamnya juga mencakup perilaku, sikap dan hubungan antar masyarakatnya yang mana hal tersebut merupakan intrumen-instrumen kebudayaan dalam konsep diplomasi budaya menurut Appel, Irony, Schmerz, dan Ziv (2008).

Kesenian Kalimantan Selatan berupa tarian, musik daerah, produk kerajinan seperti baju sasirangan, dan pertunjukan teater tradisional, serta simulasi pasar terapung merupakan sarana diplomasi budaya Pemerintah Provinsi Kalimantan Selatan dalam Festival Banjar 2018-2019. Simulasi pasar terapung yang sesuai dengan kehidupan asli masyarakat Kalimantan Selatan dan dijadikan highlight kegiatan Festival Banjar 2018-2019 dapat meninggalkan kesan yang mendalam bagi audiens sehinga diharapkan menjadi media komunikasi untuk menginformasikan mengenai budaya Kalimantan Selatan kepada masyarakat negaranya. Namun meskipun memperlihatkan kebudayaan tradisional merupakan hal yang penting untuk dilakukan, aktor-aktor kebudayaan juga perlu untuk melakukan inovasi-inovasi dalam menampilkan kebudayaannya terutama kegiatan yang dilakukan secara berkala setiap tahunnya. Inovasi yang dimaksud dapat berupa penggunaan teknologi maupun sentuhan modern dalam aktivitasnya sehingga tidak kalah dengan perkembangan zaman. Hal tersebut juga bertujuan untuk selalu menarik minat target audience yang mungkin akan menyaksikan acara tersebut lebih dari satu kali.

\section{Korps Diplomatik dan Masyarakat Asing Sebagai Target Audience Festival Banjar 2018-2019}

Target audience berarti publik yang disasar ketika diadakannya kegiatan. Target audience berkaitan langsung dengan agenda sebab target audience diidentifikasi berdasarkan misi dan tujuan dari sebuah kegiatan yang dilakukan. Jika ada kegiatan serupa dengan tujuan yang berbeda maka besar kemungkinan publik yang disasar juga berbeda (Carbone, 2017, p. 67).

Dipilihnya korps diplomatik sebagai tamu undangan bertujuan agar korps diplomatik tersebut dapat menjadi opinion leader serta memberikan promosi yang bagus kepada negaranya masing-masing mengenai Kalimantan Selatan. Antusiasme itu salah satunya ditunjukkan oleh duta besar Belanda yang kemudian tertarik datang dan melakukan liputan ke Kalimantan Selatan setelah hadir di kegiatan Festival Banjar. Hal ini diungkapkan oleh Dina Dahliana.

Pernyataan Dina Dahliana tersebut didukung oleh data sekunder yang berupa hasil liputan media Belanda yang disebutkan di atas. Liputan tersebut di unggah pada 22 April 2020 melalui kanal YouTube DiplomatTV Channel dengan judul "Wonderful Indonesia, Destination South Kalimantan”. Liputan tersebut memperlihatkan kekayaan alam Kalimantan Selatan khususnya Pasar Terapung Lok Baintan di Sungai Martapura, Festival Lokado 2019, dan bamboo rafting Loksado. 

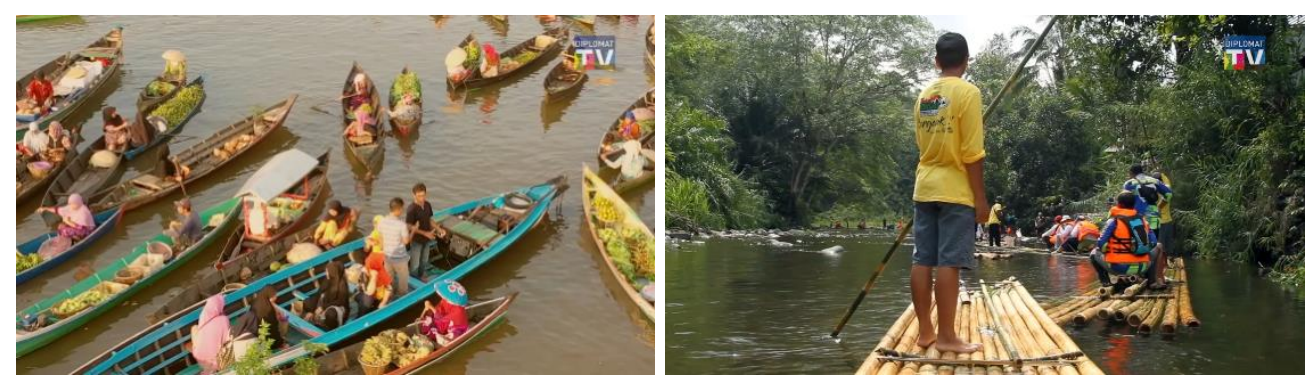

Gambar 1. Liputan DiplomatTV Channel ke Kalimantan Selatan (Sumber: DiplomatTV Channel, 2020)

Selain dikhususkan kepada korps diplomatik, M. Husni Thambrin mengatakan bahwa Festival Banjar 2018-2019 juga ditujukan kepada masyarakat dunia secara umum sebab tujuan dari Festival Banjar 2018-2019 sendiri ialah untuk mempromosikan budaya dan pariwisata Kalimantan Selatan kepada masyarakat yang lebih luas. Target audience tidak hanya menjadi penonton namun juga diajak ikut serta dalam kegiatan Festival Banjar 20182019 yaitu pada saat simulasi pasar terapung para korps diplomatik melakukan pawai simulasi pasar terapung menggunakan replika jukung, serta masyarakat asing juga ikut terlibat dalam transaksi jual beli di simulasi pasar terapung tersebut. Hal tersebut dilakukan agar audiens yang hadir dapat merasakan langsung bagaimana sebenarnya kehidupan masyarakat Kalimantan Selatan.

Menurut Azis Nurwahyudi, korps diplomatik yang hadir di Festival Banjar 2018-2019 terlihat menikmati kegiatan tersebut, bahkan mereka berharap bahwa kegiatan Festival Banjar dapat menjadi kegiatan tahunan dengan skala yang lebih besar sehingga mendatangkan jumlah audiens yang lebih besar pula.

Festival Banjar 2018-2019 memiliki target audience yaitu korps diplomatik yang menjadi tamu undangan dan masyarakat asing secara umum. Target audience tidak hanya menjadi penonton namun juga diajak ikut serta dalam kegiatan Festival Banjar 2018-2019 yaitu pada saat simulasi pasar terapung para korps diplomatik melakukan pawai simulasi pasar terapung menggunakan replika jukung, serta masyarakat asing juga ikut terlibat dalam transaksi jual beli di simulasi pasar terapung tersebut. Hal tersebut dilakukan agar audiens yang hadir dapat merasakan langsung bagaimana sebenarnya kehidupan masyarakat Kalimantan Selatan.

Korps diplomatik dapat berperan penting menjadi jembatan komunikasi dalam menyampikan budaya Indonesia khususnya budaya Kalimantan Selatan yang unik kepada masyarakat di negaranya masing-masing. Demikian halnya dengan masyarakat asing yang ada di Indonesia juga dapat dijadikan sebagai target audience yang tepat karena dengan mengikuti Festival Banjar 2018-2019, maka setelah kembali kenegaranya masing-masing mereka akan menginformasikan mengenai budaya Kalimanatan Selatan yang beraneka ragam sehingga diharapkan masyarakat lain dari negara tersebut dapat berkunjung sebagai turis untuk menikmati budaya Indonesia pada umumnya dan khususnya Kalimantan Selatan.

Hal tersebut sesuai dengan konsep yang dikemukakan oleh Jiang (2015) bahwa target audience penting untuk dilibatkan dalam kegiatan diplomasi budaya terutama yang dilakukan oleh aktor non-negara. Hal tersebut penting untuk dilakukan karena target audience akan merasa lebih dihargai kehadirannya dan yang tepenting dapat meninggalkan kesan yang mendalam, sehingga memiliki daya tarik tersendiri dibandingan dengan aktivitas diplomasi budaya lainnya. 
Paradiplomasi Festival Banjar 2018-2019

Selain elemen-elemen diplomasi budaya, Pemerintah Provinsi Kalimantan Selatan sebagai aktor sub-nasional yang merupakan agent diplomasi budaya juga terkait dengan konsep paradiplomasi.

Paradiplomasi dalam kegiatan internasional diartikan sebagai aktivitas diplomasi yang dilakukan oleh pemerintah daerah. Pengertian dalam paradiplomasi biasanya diawali dengan istilah 'subnasional', 'sub-negara bagian', atau regional (Berridge \& Llyod, 2012, p. 276).

Paradiplomasi saat ini dilihat dalam skala yang lebih luas, jika dahulu paradiplomasi erat kaitannya dengan urusan internasional yang dilakukan oleh negara federasi, seperti Kanada, Jerman, Belgia, Swiss, Australia, dan Amerika Serikat, saat ini juga terlihat nyata di beberapa negara kesatuan seperti Spanyol dan Prancis, serta Afrika Selatan, Cina, Jepang, India, Brasil, Argentina, Chili, Meksiko, dan Rusia. Bahkan provinsi-provinsi Cina saat ini dapat memberikan salah satu contoh kuat dari kegiatan-kegiatan asing yang cukup banyak yang dilakukan di tingkat daerah (Tavares, 2016).

Dari perspektif nasionalisme, paradiplomasi merupakan kegiatan yang dilakukan oleh pemerintah daerah sebagai instrumen pelengkap pembentuk identitas dan alat untuk mempromosikan kebudayaan daerahnya kepada pihak di luar negaranya tersebut (Kuznetsov, 2015, p. 68).

Berdasarkan pengertian di atas dapat dikatakan bahwa paradiplomasi merupakan aktivitas diplomasi yang dilakukan oleh aktor sub-nasional dengan tujuan mempromosikan kebudayaan daerah kepada masyarakat asing. Aktor sub-nasional yang dimaksud dalam penelitian ini yaitu Pemerintah Provinsi Kalimantan Selatan. Hal ini yang menjadi dasar bagi peneliti untuk menghubungkan konsep diplomasi budaya dan paradiplomasi.

Diplomasi budaya yang dilakukan

oleh Pemertintah Provinsi Kalimantan
Selatan dalam Festival Banjar 2018-2019 jika dikaitkan dengan perannya sebagai aktor sub-nasional dalam kerangka paradiplomasi, maka diteliti melalui dua pola pendukung aktivitas aktor sub-nasional dalam lingkup internasional menurut Duchacek (1990), yaitu tindakan lobi yang dilakukan oleh aktor sub-nasional sehingga menarik perhatian dan reaksi aktor ekstranasional, dan media asing dan domestik yang meliput tindakan aktor sub-nasional ke arena internasional.

Pola pertama, yaitu tindakan lobi yang dilakukan oleh aktor sub-nasional sehingga menarik perhatian dan reaksi aktor ekstra-nasional.

Menurut M. Husni Thambrin dari Kerukunan Bubuhan Banjar Jabodetabek, pihak Pemerintah Provinsi Kalimantan Selatan dalam melakukan lobinya, yaitu secara aktif berinteraksi dengan korps diplomatik melalui talk show interaktif pada pembukaan acara.

Menanggapi pernyataan di atas menurut Tia Sundari Waryono dari Kementerian Luar Negeri Republik Indonesia, Pemerintah Provinsi Kalimantan Selatan kurang aktif dalam melakukan koordinasi dan pendekatan dengan masyarakat asing, dapat dilihat dari minimnya informasi dalam bahasa Inggris yang diberikan kepada masyarakat asing tersebut.

Berdasarkan penjelasan para informan di atas, maka diketahui bahwa interaksi yang dilakukan oleh Pemerintah Provinsi Kalimantan Selatan kepada target audience masih berfokus pada korps diplomatik sebagai tamu undangan. Hal ini terlihat dengan dilakukannya talk show interaktif pada pembukaan bersama korps diplomatik. Sedangkan dalam taraf yang lebih luas kepada masyarakat asing, Pemerintah Provinsi Kalimantan Selatan tidak memfasilitasi secara khusus interaksi tersebut. Jika dilihat secara garis besar, hal tersebut memang sudah tepat dilakukan karena korps diplomatik merupakan salah 
satu target audience Pemerintah Provinsi Kalimantan Selatan dalam Festival Banjar 2018-2019. Namun interaksi yang dilakukan Pemerintah Provinsi Kalimantan Selatan kepada korps diplomatik juga sebaiknya diimbangi dengan interaksinya kepada masyarakat asing. Seperti halnya memberikan beberapa informasi dalam bahasa Inggris berupa materi promosi, seperti brosur atau booklet, maupun informasi lisan seperti mengadakan sesi tanya jawab dengan masyarakat asing sebagai penonton, maupun menyediakan booth khusus yang dapat menjadi tempat singgah masyarakat asing yang ingin tahu lebih lanjut mengenai budaya dan pariwisata Kalimantan Selatan.

Pola kedua, yaitu media asing dan domestik yang meliput tindakan aktor subnasional ke arena internasional.

Sebagai agent diplomasi budaya yang berperan untuk mempromosikan kegiatan, maka Pemerintah Provinsi Kalimantan Selatan mengundang beberapa media nasional dan media lokal untuk melakukan peliputan di Festival Banjar 2018-2019. Hal tersebut diungkapkan oleh Dina Dahliana.

Azis Nurwahyudi juga mengatakan bahwa sebelum diundang dalam pelaksanaan acara, media tersebut diundang terlebih dahulu dalam konferensi pers. Konferensi pers dilakukan secara langsung oleh Wakil Menteri Luar Negeri dan panitia pelaksana Festival Banjar 2018-2019 sehingga peliputan media dalam pelaksanaan acara akan lebih terarah.

Menurut Denny P. Sinaga, selain media nasional dan media lokal, media asing juga perlu untuk diikutsertakan dalam Festival Banjar 2018-2019. Namun selain media mainstream yang terpenting ialah media sosial karena media sosial yang saat ini memiliki konektivitas terbesar terhadap masyarakat di seluruh dunia.

Pelaksanaan Festival Banjar 20182019 telah melibatkan media nasional dan media lokal dalam proses peliputan kegiatannya. Hal ini sudah tepat dilakukan, meskipun kehadiran media asing juga diperlukan sehingga dapat menunjang tujuan diadakannya Festival Banjar 2018-2019 yaitu untuk mempromosikan budaya dan pariwisata Kalimantan Selatan ke masyarakat yang lebih luas. Tidak hanya berupa media mainstream, namun media sosial juga dapat dipergunakan. Kehadiran media asing menjadi penting sebab peliputannya akan dilakukan menggunakan bahasa Inggris yang mungkin lebih dipahami oleh masyarakat asing. Keterlibatan media nasional dan media lokal tersebut dapat membantu aktivitas agent dalam hal ini Pemerintah Provinsi Kalimantan Selatan sabagai aktor sub-nasional untuk menyebarluaskan kegiatan Festival Banjar 2018-2019 kepada masyarakat asing yang ada di Indonesia saat itu.

\section{SIMPULAN}

Berdasarkan hasil penelitian dan analisis data yang dilakukan mengenai Diplomasi Budaya Pemerintah Provinsi Kalimantan Selatan dalam Festival Banjar 2018-2019 dengan menggunakan konsep diplomasi budaya dan paradiplomasi, maka dapat disimpulkan bahwa Festival Banjar 2018-2019 merupakan wujud diplomasi budaya yang dilakukan oleh aktor subnasional dalam hal ini Pemerintah Provinsi Kalimantan Selatan.

Festival Banjar merupakan praktik agent diplomasi budaya yang menggunakan mixed model, agenda untuk mempromosikan budaya dan pariwisata Kalimantan Selatan, vehicle melalui kesenian Kalimantan Selatan dan simulasi pasar terapung, dan target audience yaitu korps diplomatik dan masyarakat asing. Pemerintah Provinsi Kalimantan Selatan sebagai aktor sub-nasional yang melakukan aktivitas diplomasi budaya terkait dengan konsep paradiplomasi dimana pelaksanaannya melibatkan dua pola pendukung, yaitu tindakan lobi yang dilakukan oleh aktor sub-nasional sehingga 
menarik perhatian dan reaksi aktor ekstranasional, dan media asing dan domestik yang meliput tindakan aktor sub-nasional ke arena internasional. Interaksi dilakukan oleh Pemerintah Provinsi Kalimantan Selatan kepada korps diplomatik melalui talk show interaktif, dan media yang terlibat dalam peliputan Festival Banjar 2018-2019 yaitu media nasional dan media lokal, berupa media mainstream dan media online.

Penelitian ini juga menunjukkan bahwa saat ini telah ada perkembangan dalam dinamika hubungan internasional dimana negara sudah bukan lagi menjadi satu-satunya aktor utama didalam sistem internasional, melainkan juga ada aktor nonnegara yang berperan penting dalam melakukan aktivitas diplomasi budaya.

Festival Banjar 2018-2019 dalam pelaksanaannya telah sesuai dengan konsep diplomasi budaya dengan empat elemennya yaitu agent, agenda, vehicle, dan target audience meskipun terdapat beberapa hal yang harus ditingkatkan. Rekomendasi yang dapat diberikan kepada Pemerintah Provinsi Kalimantan Selatan, yaitu dalam elemen agent yang terkait dengan paradiplomasi, bahwa sebaiknya Pemerintah Provinsi Kalimantan Selatan melakukan interaksi yang lebih aktif kepada masyarakat asing, baik menyediakan materi promosi dalam bahasa Inggris ataupun memberi informasi lisan dalam sesi tanya jawab atau membuat booth khusus bagi masyarakat asing. Selain itu Pemerintah Provinsi Kalimantan Selatan juga sebaiknya memperluas cakupan penggunaan media dengan melibatkan media asing dalam peliputan Festival Banjar, berupa media online dan media sosial seperti YouTube dan Instagram. Selain itu dalam elemen vehicle, Pemerintah Provinsi Kalimantan Selatan sebaiknya melakukan inovasi dalam aktivitas kebudayaannya, seperti memanfaatkan penggunakan teknologi maupun memberikan sentuhan modern sehingga tidak tertinggal dengan perkembangan zaman dan kebudayaan yang ditampilkan tidak bersifat monoton.

Peneliti juga mengharapkan agar diplomasi jenis ini dapat dikembangkan oleh pemerintah daerah lainnya di Indonesia, mengingat diplomasi saat ini tidak hanya dilakukan oleh pemerintah pusat, sehingga semakin banyak cara yang dapat ditempuh untuk mempromosikan budaya dan pariwisata daerah kepada masyarakat asing.

\section{DAFTAR PUSTAKA}

Ada, S. (2017). Cultural diplomacy: from showcase to intercultural dialogue. Dalam M. D. Šešić, Cultural Diplomacy: Arts, Festivals and Geopolitics (pp. 51-59). Belgrade: Creative Europe Desk Serbia, Ministry of Culture and Media of Republic of Serbia.

Ang, I., Isar, Y. R., \& Mar, P. (2015). Cultural diplomacy: beyond the national interest? International Journal of Cultural Policy, 21(4), 365-381. Diperoleh dari https://www.tandfonline.com/doi/ful 1/10.1080/10286632.2015.1042474

Appel, R., Irony, A., Schmerz, S., \& Ziv, A. (2008). Cultural diplomacy: An Important but Neglected Tool in Promoting Israel's Public Image. $N$ : Argov Fellows Program In Leadership And Diplomacy. Diperoleh dari http://portal.idc.ac.il/sitecollectiond ocuments/cultural_diplomacy_semi nar_paper1.pdf

Badan Pusat Statistik. (2018). Jumlah Tamu Asing pada Hotel Bintang (Ribu Orang), 2016-2018. Diperoleh dari website Badan Pusat Statistik: https://www.bps.go.id/indicator/16/ 310/1/jumlah-tamu-asing-padahotel-bintang.html

Berridge, G. R., \& Llyod, L. (2012). The Palgrave Macmillan: Dictionary of Diplomacy (3rd ed.). Palgrave Macmillan. 
Carbone, F. (2017). International tourism and cultural diplomacy: A new conceptual approach towards global mutual understanding and peace through tourism. Tourism, 61-74. Diperoleh dari https://hrcak.srce.hr/index.php?sho $\mathrm{w}=$ clanak\&id_clanak_jezik $=263329$

Cull, N. J. (2009). Public Diplomacy: Lessons from the Past. Los Angeles: University of Southern California.

DiplomatTV Channel. (2020, April 22). Wonderful Indonesia, Destination South Kalimantan [Video file]. Retrieved Juni 29, 2020, from https://www.youtube.com/watch?v= xfVRzBKe9NQ

Direktorat Warisan dan Diplomasi Budaya Direktorat Jenderal Kebudayaan Kementerian Pendidikan dan Kebudayaan. (2018). Pedoman Diplomasi Budaya. Jakarta.

Duchacek, I. D. (1990). Perforated Sovereignties: Towards a Typology of New Actors in International Relations. Dalam H. J. Soldatos, Federalism and International Relations: The Role of Subnational Units (pp. 1-33). New York: Oxford University Press Inc.

Emilia, R. (2013). Praktek Diplomasi. Jakarta: Baduose Media.

Jiang, H. (2015). Ethical Visions for Public Diplomacy as International Public Relations. In S.-U. Y. Guy J. Golan, International Public Relations and Public Diplomacy: Communication and Engagement (pp. 167-186). New York: Peter Lang Publishing, Inc.

Kuznetsov, A. S. (2015). Theory and Practice of Paradiplomacy: Subnational Governments in International Affairs. London: Routledge.

Lestariningsih, T. E. (2016). Wonderful Indonesia Festival 2015 di Thailand Sebagai Diplomasi Kebudayaan Indonesia. Transformasi No. 29, 56-
159. Diperoleh dari http://ejurnal.unisri.ac.id/index.php/ Transformasi/article/view/1747

Mukti, T. A. (2013). Paradiplomacy: Kerjasama Luar Negeri oleh Pemda di Indonesia. Yogyakarta: The Phinisi Press.

Neuman, W. L. (2014). Social Research Methods: Qualitative and Quantitative Approaches. London: Pearson.

Nye, J. S. (2004). Soft Power: The Means to Success in World Politics. New York: Public Affairs.

Riordan, S. (2005). Dialogue-based Public Diplomacy: a New Foreign Policy Paradigm? Dalam J. Melissen, The New Public Diplomacy: Soft Power in International Relations (pp. 180195). Palgrave Macmillan.

Rostanti, Q. (2017, Agustus 3). Budaya Jadi Penarik Wisatawan Mancanegara Kunjungi Indonesia. Diperoleh pada Januari 11, 2020, dari https://www.republika.co.id/berita/g aya-hidup/pesonaindonesia/17/08/03/ou3jxi425budaya-jadi-penarik-wisatawanmancanegara-kunjungi-indonesia

Sabekti, K. (2003). Seni Budaya, Sarana Menjalin Persahabatan. Dalam H. Sudrajat, Dinamika Diplomasi Indonesia dalam Praktik (pp. 66-70). Bekasi: Megapoin.

Suharyadi, I. (2016). Peran Penting Asia Africa Smart City Summit (AASCS) 2015 Terhadap Perkembangan Paradiplomasi Kota Bandung. Global Vol. 18 No. 1, 95-107. Diperoleh dari http://www.global.ir.fisip.ui.ac.id/in dex.php/global/article/view/37

Sumiyati, S., \& Murdiyanto, L. (2018). Strategi Komunikasi Pemasaran Pariwisata Untuk Meningkatkan Kunjungan Wisatawan Di Pantai Suwuk Kabupaten Kebumen. Wacana: Jurnal Ilmiah Ilmu 
Komunikasi, 17(2), 171-180. Zamorano, M. M. (2016). Reframing Diperoleh dari https://journal.moestopo.ac.id/index. $\mathrm{php} /$ wacana/article/view/629

Tavares, R. (2016). Paradiplomacy: Cities Cultural Diplomacy: The Instrumentalization of Culture under the Soft Power Theory. Culture and States as Global Players. New Unbound, 8(2), 165-186. York: Oxford University Press. 